\title{
Fertility in male medulloblastoma survivors: closing the gaps in counseling
}

This article was published in the following Dove Press journal:

Clinical Oncology in Adolescents and Young Adults

2 December 2013

Number of times this article has been viewed

\author{
Leena Nahata' \\ Richard $\mathrm{NYu}^{2}$ \\ lan $\mathrm{P}$ Dumont ${ }^{3,4}$ \\ Peter E Manley ${ }^{3,4}$ \\ Laurie E Cohen ${ }^{1,3,4}$ \\ 'Division of Endocrinology, \\ ${ }^{2}$ Department of Urology, Department \\ of Medicine, Boston Children's \\ Hospital, ${ }^{3}$ Division of Hematology/ \\ Oncology, Department of Medicine, \\ Boston Children's Hospital, \\ ${ }^{4}$ Department of Pediatric Oncology, \\ Dana-Farber Cancer Institute, Boston, \\ MA, USA
}

Background: Pediatric medulloblastoma patients have high survival rates and are at risk for treatment-related sequelae, including infertility, emphasizing the need for fertility counseling. This cohort is less likely to pursue higher education, marry, and live independently, which may impact fertility counseling. Our goal was to explore fertility-related concerns in medulloblastoma survivors and counseling practices among providers.

Methods: This study was performed at the Dana-Farber/Children's Hospital Cancer Center in Boston, Massachusetts. Surveys were administered to male pediatric medulloblastoma survivors aged 18 years and older and pediatric neuro-oncology practitioners. Medical records were reviewed to determine treatment protocols and documentation of fertility counseling. Data analysis was descriptive.

Results: Fourteen male medulloblastoma survivors and six neuro-oncology practitioners completed the study. All patients had received central nervous system irradiation and adjuvant chemotherapy with at least one alkylating agent. Five (83\%) practitioners stated that they discussed fertility with all survivors at most visits. Eight (57\%) medulloblastoma survivors stated that they had received fertility counseling at initial diagnosis. Six (43\%) stated that fertility had been discussed since treatment had ended. The majority $(>70 \%)$ of survivors reported a desire to have children and were open to learning more about their fertility status. Fertility counseling was documented in survivorship visits in only $46 \%$ of subjects.

Conclusion: Most of our subjects had no documented fertility-related discussions after completing treatment and could not recall any fertility counseling during survivorship; the majority wished to learn more about their fertility status. This suggests that the frequency with which practitioners initiate these discussions may be inadequate.

Keywords: infertility, fertility counseling, medulloblastoma, survivorship

\section{Introduction}

Central nervous system tumors are the second most common neoplasms in childhood, and $25 \%-30 \%$ of these tumors are medulloblastomas. ${ }^{1}$ Advances in therapeutic regimens have resulted in cure rates ranging from $60 \%$ to $85 \%, 2,3$ and significant morbidities need to be addressed in adulthood, such as sexual dysfunction and infertility. ${ }^{4,5}$ Hypogonadism resulting from oncologic treatment in these patients may be primary (due to chemotherapy) or secondary (due to radiation to the hypothalamic/pituitary axis). Primary gonadal damage is often seen in medulloblastoma patients who have received adjuvant chemotherapy. ${ }^{1,2,6}$ In a study of male brain tumor survivors, the median inhibin B level in patients who had been treated with radiation and chemotherapy was $86 \mathrm{pg} / \mathrm{mL}$, which is indicative of impaired spermatogenesis. ${ }^{2}$ 
Although data about fertility preservation in the pediatric medulloblastoma population are limited, several studies have been done in patients with other types of pediatric cancer. Sperm banking is an effective method of preserving fertility, and pubertal males with cancer are thus encouraged to bank sperm prior to starting oncologic treatment. ${ }^{7,8}$ Additionally, fertility counseling and sperm cryopreservation may help young adults cope with the cancer diagnosis ${ }^{9}$ and decrease fears about having children. ${ }^{10}$ Unfortunately, sperm banking has been strikingly underutilized, ${ }^{11-13}$ largely due to inconsistent fertility counseling practices ${ }^{8,12-15}$ despite guidelines from the American Society of Clinical Oncology and the American Academy of Pediatrics. ${ }^{16,17}$

Many barriers to providing adequate fertility counseling for pediatric cancer patients have been identified among practitioners, including urgency to start oncologic treatment, inadequate time and knowledge about preservation options, difficulty due to the sensitive nature of the topic, and lack of age-appropriate facilities for adolescent patients. ${ }^{18}$ Many pediatric patients are too young and/or immature to consider plans for parenthood. These discussions may be even more challenging in medulloblastoma patients, who often have neurologic symptoms such as headaches, ataxia, and vomiting. ${ }^{19}$ Therefore, parents and practitioners frequently play active roles in the initial discussions and decisions about fertility preservation. Years later, many of these pediatric cancer survivors have a limited understanding about those initial discussions and remain uncertain of their fertility status. ${ }^{20}$

Guilt, low self-esteem, and anxiety surrounding the possibility of infertility may affect these survivors' ability to maintain intimate relationships, ${ }^{20}$ and they may be unaware of available interventions for reduced fertility, such as testicular sperm extraction and in vitro fertilization/intracytoplasmic sperm injection. ${ }^{5}$ Studies have shown that medulloblastoma survivors frequently have adverse neurocognitive and psychosocial effects from craniospinal radiation, and are less likely to be highly educated, have steady employment, live independently, date, and marry. ${ }^{21,22}$ These men may thus be less inclined to initiate discussions about fertility with their families and practitioners, making it appear that they are not concerned about these issues.

The goals of this study were to examine fertility counseling practices of pediatric neuro-oncology providers involved in the care of male pediatric medulloblastoma patients and to evaluate fertility concerns of male medulloblastoma survivors.

\section{Materials and methods}

This was a cross-sectional study at a single institution, consisting of surveys administered to male pediatric medulloblastoma survivors and pediatric neuro-oncology practitioners.

\section{Patient survey methods}

Institutional review board approval was obtained to conduct a telephone survey of all male medulloblastoma survivors aged 18 years and older seen in the past 20 years at the Stop and Shop Family Pediatric Brain Tumor long-term follow-up clinic at Dana-Farber/Children's Hospital Cancer Center (DF/CHCC) in Boston, Massachusetts.

Inclusion criteria were as follows: male gender, history of medulloblastoma, and current age $\geq 18$ years. Subjects were excluded if they had a documented history of intellectual disability or pervasive developmental disorder, or if prior neurologic testing had shown a reading level below 8th grade ability. Subjects were sent a letter describing the study with an opt-out card. A single study team member then contacted the subjects via telephone to complete the surveys.

\section{Practitioner survey methods}

All of the pediatric neuro-oncology medical and pediatric nurse practitioners at $\mathrm{DF} / \mathrm{CHCC}$ were asked to complete a survey about their fertility counseling practices in males with medulloblastoma.

\section{Additional data collection and analysis}

Retrospective chart review was completed to determine treatment protocols and whether fertility counseling had been documented before and after treatment. Data analysis was descriptive.

\section{Results}

\section{Patient survey data}

Twenty-one male medulloblastoma survivors met the inclusion criteria. None were eliminated based on the exclusion criteria. Three subjects returned the opt-out cards, and four were unable to be contacted using the phone numbers in their medical records. All of the remaining subjects $(n=14)$ who were contacted agreed to participate; survey results are presented in Table 1. The current age of this sample was 18-32 (median 24) years. Age at medulloblastoma diagnosis was 3-19 (median 13.5) years. 
Table I Fertility concerns among medulloblastoma survivors $(n=14)$

\begin{tabular}{|c|c|c|}
\hline \multicolumn{2}{|c|}{ Question } & $\begin{array}{l}\text { Response, n (\%) } \\
\text { Yes }\end{array}$ \\
\hline $\mathrm{I}$ & Was infertility discussed at initial diagnosis? & $8(57)$ \\
\hline \multirow[t]{3}{*}{2} & Was sperm banking discussed at initial diagnosis? & $6(43)$ \\
\hline & $\begin{array}{l}\text { If sperm banking was discussed, was an attempt } \\
\text { to sperm bank made? }\end{array}$ & $4(67)^{*}$ \\
\hline & $\begin{array}{l}\text { If an attempt was made, was an adequate sample } \\
\text { produced? }\end{array}$ & $3(75)^{*}$ \\
\hline 3 & Has fertility been discussed since treatment ended? & $6(43)$ \\
\hline 4 & $\begin{array}{l}\text { Have you been in a serious romantic relationship } \\
\text { after treatment? }\end{array}$ & $6(43)$ \\
\hline 5 & Are you concerned about fertility? & I (7) \\
\hline 6 & Do you want to have children? & $10(7 \mid)$ \\
\hline 7 & Have you ever tried to have a biological child? & $0(0)$ \\
\hline 8 & $\begin{array}{l}\text { Are you interested in learning more about your } \\
\text { fertility status? }\end{array}$ & II (79) \\
\hline
\end{tabular}

Note: *The percentages are based on the total number in question 2 .

\section{Practitioner survey data}

All six practitioners (two nurse practitioners and four attending physicians) from the Pediatric Neuro-Oncology program at DF/CHCC completed surveys about their fertility counseling practices at time of medulloblastoma diagnosis and during survivorship (Table 2), and about barriers to fertility counseling (Tables 3 and 4).

\section{Electronic medical record data}

Treatment regimens were reviewed for this cohort as a whole. All patients had been treated with 23.4-36 Gy whole brain and spine radiation with a boost to the posterior fossa to $50.4-54$ Gy. They had received adjuvant chemotherapy with cisplatin, vincristine, and lomustine $\left(450-600 \mathrm{mg} / \mathrm{m}^{2}\right)$ and/or cyclophosphamide $\left(4.5-24 \mathrm{~g} / \mathrm{m}^{2}\right)$. Based on these treatments, all patients contacted were felt to be at risk for infertility. ${ }^{1,7}$

Medical records from the initial oncologic consultation were found for 12 of 14 patients. In six of the 12 evaluable cases $(50 \%)$, infertility was mentioned as a potential side effect of oncologic treatment. In five of the other six cases where infertility was not discussed, the patients were prepubertal at the time of diagnosis.

Documentation from survivorship visits was found in 13 of 14 patients. In six of 13 subjects (46\%), discussions with the survivors about fertility issues were documented. In five patients' records (38\%), there was no mention of fertility. In two cases (15\%), the possibility of infertility was mentioned in the notes but it was unclear whether this had been discussed with the patient.

\section{Discussion}

Preservation of reproductive capacity is recognized as an important component of a cancer survivor's quality of life. The majority of patients in our study had been treated with central nervous system radiation and alkylating agents (at doses that have been reported to cause gonadal dysfunction), putting them at risk for primary and secondary hypogonadism..$^{23,24}$ Fortunately, most adolescent patients in our study had received pretreatment fertility counseling, and the majority of those boys did attempt to bank sperm.

Fertility also needs to be readdressed after treatment is complete, as many pediatric cancer survivors may not recall the potential side effects of their oncologic treatment once they reach adulthood and consider having children. ${ }^{20,25}$ Additionally, some patients may have transient suppression of spermatogenesis after treatment with gradual recovery over time, highlighting the importance of routine surveillance

Table 2 Frequency of fertility counseling $(n=6)$

\begin{tabular}{|c|c|c|c|c|c|c|}
\hline \multirow[t]{2}{*}{ Question } & \multicolumn{6}{|c|}{ Response, n (\%) } \\
\hline & Always & & time & Sometimes & Rarely & Never \\
\hline \multirow{3}{*}{$\begin{array}{l}\text { In male patients with medulloblastoma, } \\
\text { infertility is a side effect that is seen } \\
\text { I discuss fertility preservation } \\
\text { with families of male medulloblastoma } \\
\text { patients } \geq I 3 \text { years }\end{array}$} & $0(0)$ & & & $5(83)$ & $0(0)$ & $0(0)$ \\
\hline & $0(0)$ & & & $2(33)$ & $2(33)$ & $0(0)$ \\
\hline & \multicolumn{2}{|c|}{$\begin{array}{l}\text { With all survivors, } \\
\text { routinely, at all visits }\end{array}$} & \multicolumn{2}{|c|}{$\begin{array}{l}\text { With all survivors, } \\
\text { at some visits }\end{array}$} & \multicolumn{2}{|c|}{$\begin{array}{l}\text { Only in survivors who raise } \\
\text { a concern about their fertility }\end{array}$} \\
\hline $\begin{array}{l}\text { In male patients } 18 \text { years and older } \\
\text { who have completed treatment } \\
\text { for medulloblastoma, I initiate } \\
\text { discussions about fertility }\end{array}$ & $I(17)$ & & \multicolumn{2}{|l|}{$4(67)$} & \multicolumn{2}{|l|}{ I (I7) } \\
\hline
\end{tabular}


Table 3 Barriers to fertility counseling at time of diagnosis $(n=6)$

\begin{tabular}{|c|c|c|c|c|}
\hline \multirow[t]{2}{*}{ Question } & \multicolumn{4}{|c|}{ Response, n (\%) } \\
\hline & $\begin{array}{l}\text { Agree } \\
\text { strongly }\end{array}$ & $\begin{array}{l}\text { Agree } \\
\text { somewhat }\end{array}$ & $\begin{array}{l}\text { Disagree } \\
\text { somewhat }\end{array}$ & $\begin{array}{l}\text { Disagree } \\
\text { strongly }\end{array}$ \\
\hline $\begin{array}{l}\text { All male patients undergoing cancer treatment with infertility as a potential side effect } \\
\text { should be offered sperm banking }\end{array}$ & $3(50)$ & $3(50)$ & $0(0)$ & $0(0)$ \\
\hline My patients are typically too ill to attempt sperm banking & $0(0)$ & $2(33)$ & $2(33)$ & $2(33)$ \\
\hline The urgency to start treatment makes it difficult to discuss and complete sperm banking & $0(0)$ & $3(50)$ & $2(33)$ & $I(I 7)$ \\
\hline I do not have time in a busy clinic to discuss sperm banking adequately & $0(0)$ & $0(0)$ & $5(83)$ & I (I7) \\
\hline I do not have knowledge/information to counsel patients adequately about sperm banking & $0(0)$ & $4(66)$ & $2(33)$ & $0(0)$ \\
\hline $\begin{array}{l}\text { It is uncomfortable to discuss sperm banking with patients because it is such an emotional } \\
\text { and intimate topic }\end{array}$ & $0(0)$ & $\mathrm{I}(\mathrm{I7})$ & $2(33)$ & $3(50)$ \\
\hline Sperm banking is the only option I can offer to my patients for fertility preservation & $0(0)$ & $2(33)$ & $3(50)$ & $I(I 7)$ \\
\hline $\begin{array}{l}\text { The success rates of infertility treatments making use of frozen sperm are too young } \\
\text { to justify banking sperm }\end{array}$ & $0(0)$ & $0(0)$ & $2(33)$ & $4(66)$ \\
\hline I am less likely to discuss fertility preservation with patients whose overall prognosis is poor & $\mathrm{I}(\mathrm{I})$ & $2(33)$ & $3(50)$ & $0(0)$ \\
\hline
\end{tabular}

of the hypothalamic-pituitary-gonadal axis. ${ }^{26}$ Childhood cancer survivors are known to have anxiety about interpersonal relationships, sexual function, and fatherhood. ${ }^{20,27}$ Misconceptions about their fertility status may lead to unnecessary anxiety, or in other cases, may result in unintentional pregnancies. ${ }^{20}$ Further, moderate to severe oligospermia has been shown to progress to azoospermia over time. ${ }^{11}$ Therefore, patients with persistent moderate to severe oligospermia after treatment should consider banking their sperm if this was not completed prior to therapy.

Medulloblastoma survivors who have received craniospinal irradiation and gonadotoxic chemotherapeutic agents, such as the subjects in our study, may have primary gonadal damage that is underdiagnosed due to follicle-stimulating hormone levels that appear to be "normal" or even low due to superimposed secondary hypogonadism. Inhibin B levels may help in assessing gonadal function, ${ }^{2,28}$ but have been shown in some studies to have low specificity and positive predictive value for azoospermia, ${ }^{29}$ and thus should be interpreted in conjunction with careful physical examination and semen analysis. Relying on biochemical testing alone to counsel these patients about their fertility status can provide inadequate or even inaccurate information; these survivors

Table 4 Barriers to fertility counseling in survivorship $(n=6)$

\begin{tabular}{lll}
\hline Prompt & \multicolumn{2}{l}{ Response, $\mathbf{n}(\%)$} \\
\hline $\begin{array}{l}\text { I am less likely to initiate a discussion } \\
\text { about fertility in survivors who: }\end{array}$ & True & False \\
Have never had a serious romantic relationship & $0(0)$ & $6(100)$ \\
Have never expressed a desired to have children & I (I7) & $5(83)$ \\
Have never lived independently & $2(33)$ & $4(67)$ \\
Have banked sperm in the past & $0(0)$ & $6(100)$ \\
Have not banked sperm in the past & $0(0)$ & $6(100)$ \\
\hline
\end{tabular}

should thus be referred to fertility specialists for a more detailed evaluation. Given that the majority of our pracititioners felt that they had inadequate information to counsel patients about fertility preservation, routinely involving a fertility specialist should be considered, as suggested by the American Academy of Pediatrics. ${ }^{17}$

Consistent with studies in other pediatric cancer patients, there was significant variation between our providers in their reported frequency of fertility counseling. ${ }^{13-15,17}$ In survivorship, most practitioners stated that they discuss fertility with all survivors at some visits. However, our chart review demonstrated that a significant number of subjects had no documented discussions about their fertility status with their providers since treatment had ended, and in the transition to adulthood. This discrepancy suggests that the frequency with which practitioners initiate these discussions may be inadequate, or that miscommunication exists between practitioners and survivors surrounding these topics. Perhaps because medulloblastoma survivors are less likely to complete education, have careers, live independently, and marry, ${ }^{21,22}$ their health care providers may actually initiate discussions about fertility less often than they realize.

Although the majority of medulloblastoma survivors in our study stated that they were not concerned about fertility, most of them expressed a desire to have children and were open to learning more about their fertility status. This was true even in survivors who had not recently been in a serious romantic relationship, and in those who had never lived independently. Of note, some of these factors were identified by practitioners as influencing whether they would initiate a discussion about fertility. This discrepancy is similar to findings in previous studies of other cancer survivors, where many survivors stated that they were "uncertain" about their 
fertility status or just “didn't think about it", but the majority expressed a desire to have children. ${ }^{20}$ Once again, this highlights the need to routinely incorporate fertility counseling into survivorship visits, rather than relying on external factors or waiting for the patient to express a concern to prompt these discussions.

The strengths of this study include a high recruitment rate, and the simultaneous collection of data from survivors and practitioners. Importantly, this is one of the few studies that has focused on fertility concerns and counseling in pediatric medulloblastoma survivors, who certainly face unique challenges compared with other childhood cancer survivors. As stated above, these young men are less likely to be employed, live independently, and get married, ${ }^{21,22}$ which may affect how their families, friends, and health care providers perceive their desire to have children.

The main limitation of this study was the small sample size of the cohort, and the fact that the findings represent a single-center experience. Additionally, there may have been recall bias affecting survey responses among the medulloblastoma survivors. Also, fertility may have been discussed with some of these patients by other providers, such as endocrinologists. We were unable to survey these other providers, or obtain recent hormonal evaluations, given that many of our survivors have transitioned to pediatric and adult endocrinologists at other institutions. A potential direction for future research would be to perform a prospective study in this cohort, obtaining biochemical evaluations and semen analyses in medulloblastoma survivors, as there are minimal recent fertility data in this cohort. Face-to-face interviews could also be conducted to gather additional information about survivors' sexual history and function and feelings about marriage, because these factors may have a significant impact on fertility and the desire to have children.

Despite these limitations, our data demonstrate that oncologists should routinely initiate discussions about fertility both prior to treatment and during survivorship, regardless of the relationship/living situation of the individual patient, and even in those who may not appear to be thinking about these issues. These patients and survivors should be made aware of their gonadal function and risk for reduced fertility, in addition to options for sperm preservation. ${ }^{5,20,30}$ As has been recommended in previous studies, practitioners may benefit from formal education and training in how to initiate fertility counseling. ${ }^{15,31}$ Providers should also consider referring patients and survivors to fertility specialists, and/or to support agencies such as Fertile Hope (www.fertilehope.org) and the Livestrong Foundation (www.livestrong.org) for additional information and psychosocial support. ${ }^{17,20}$ Larger studies of pediatric brain tumor survivors may help optimize fertility counseling in this unique population. Standardized fertility counseling guidelines should be implemented to ensure best clinical practice.

\section{Disclosure}

The authors report no conflicts of interest in this work.

\section{References}

1. Ahmed SR, Shalet SM, Campbell RH, Deakin DP. Primary gonadal damage following treatment of brain tumors in childhood. J Pediatr. 1983;103(4):562-565

2. Schmiegelow M, Lassen S, Poulsen HS, et al. Gonadal status in male survivors following childhood brain tumors. J Clin Endocrinol Metab. 2001;86(6):2446-2452.

3. Packer RJ, Gajjar A, Vezina G, et al. Phase III study of craniospinal radiation therapy followed by adjuvant chemotherapy for newly diagnosed average-risk medulloblastoma. J Clin Oncol. 2006;24(25): 4202-4208.

4. Romerius P, Stahl O, Moell C, et al. Hypogonadism risk in men treated for childhood cancer. J Clin Endocrinol Metab. 2009;94(11): 4180-4186.

5. Kenney LB, Cohen LE, Shnorhavorian M, et al. Male reproductive health after childhood, adolescent, and young adult cancers: a report from the Children's Oncology Group. J Clin Oncol. 2012;30(27): 3408-3416.

6. Pasqualini T, Diez B, Domene H, et al. Long-term endocrine sequelae after surgery, radiotherapy, and chemotherapy in children with medulloblastoma. Cancer. 1987;59(4):801-806.

7. Green DM, Kawashima T, Stovall M, et al. Fertility of male survivors of childhood cancer: a report from the Childhood Cancer Survivor Study. J Clin Oncol. 2010;28(2):332-339.

8. Hourvitz A, Goldschlag DE, Davis OK, Gosden LV, Palermo GD, Rosenwaks Z. Intracytoplasmic sperm injection (ICSI) using cryopreserved sperm from men with malignant neoplasm yields high pregnancy rates. Fertil Steril. 2008;90(3):557-563.

9. Saito K, Suzuki K, Iwasaki A, Yumura Y, Kubota Y. Sperm cryopreservation before cancer chemotherapy helps in the emotional battle against cancer. Cancer. 2005;104(3):521-524.

10. Hohmann C, Borgmann-Staudt A, Rendtorff R, et al. Patient counselling on the risk of infertility and its impact on childhood cancer survivors: results from a national survey. J Psychosoc Oncol. 2011;29(3): 274-285.

11. Bak CW, Song SH, Yoon TK, Lim JJ, Shin TE, Sung S. Natural course of idiopathic oligozoospermia: comparison of mild, moderate and severe forms. Int J Urol. 2010;17(11):937-943.

12. Rabah DM, Wahdan IH, Merdawy A, Abourafe B, Arafa MA. Oncologists' knowledge and practice towards sperm cryopreservation in Arabic communities. J Cancer Surviv. 2010;4(3):279-283.

13. Schover LR, Brey K, Lichtin A, Lipshultz LI, Jeha S. Knowledge and experience regarding cancer, infertility, and sperm banking in younger male survivors. J Clin Oncol. 2002;20(7):1880-1889.

14. Achille MA, Rosberger Z, Robitaille R, et al. Facilitators and obstacles to sperm banking in young men receiving gonadotoxic chemotherapy for cancer: the perspective of survivors and health care professionals. Hum Reprod. 2006;21(12):3206-3216.

15. Quinn GP, Vadaparampil ST, Gwede CK, et al. Discussion of fertility preservation with newly diagnosed patients: oncologists' views. J Cancer Surviv. 2007;1(2):146-155.

16. Lee SJ, Schover LR, Partridge AH, et al. American Society of Clinical Oncology recommendations on fertility preservation in cancer patients. J Clin Oncol. 2006;24(18):2917-2931. 
17. Fallat ME, Hutter J; American Academy of Pediatrics Committee on Bioethics, American Academy of Pediatrics Section on Hematology/ Oncology, American Academy of Pediatrics Section on Surgery. Preservation of fertility in pediatric and adolescent patients with cancer. Pediatrics. 2008;121(5):e1461-e1469.

18. Nahata L, Cohen LE, Yu RN. Barriers to fertility preservation in male adolescents with cancer: it's time for a multidisciplinary approach that includes urologists. Urology. 2012;79(6):1206-1209.

19. Park TS, Hoffman HJ, Hendrick EB, Humphreys RP, Becker LE. Medulloblastoma: clinical presentation and management. Experience at the hospital for sick children, Toronto, 1950-1980. J Neurosurg. 1983;58(4):543-552.

20. Zebrack BJ, Casillas J, Nohr L, Adams H, Zeltzer LK. Fertility issues for young adult survivors of childhood cancer. Psychooncology. 2004; 13(10):689-699.

21. Maddrey AM, Bergeron JA, Lombardo ER, et al. Neuropsychological performance and quality of life of 10 year survivors of childhood medulloblastoma. J Neurooncol. 2005;72(3):245-253.

22. Edelstein K, Spiegler BJ, Fung S, et al. Early aging in adult survivors of childhood medulloblastoma: long-term neurocognitive, functional, and physical outcomes. Neurooncology. 2011;13(5):536-545.

23. Romerius P, Stahl O, Moell C, et al. High risk of azoospermia in men treated for childhood cancer. Int J Androl. 2011;34(1):69-76.

24. Stahl PJ, Stember DS, Hsiao W, Schlegel PN. Indications and strategies for fertility preservation in men. Clin Obstet Gynecol. 2010;53(4): 815-827.
25. Landier W, Wallace WH, Hudson MM. Long-term follow-up of pediatric cancer survivors: education, surveillance, and screening. Pediatr Blood Cancer. 2006;46(2):149-158.

26. Lampe H, Horwich A, Norman A, Nicholls J, Dearnaley DP. Fertility after chemotherapy for testicular germ cell cancers. J Clin Oncol. 1997;15(1):239-245.

27. Zebrack BJ, Foley S, Wittmann D, Leonard M. Sexual functioning in young adult survivors of childhood cancer. Psychooncology. 2010;19(8):814-822.

28. Cuny A, Trivin C, Brailly-Tabard S, et al. Inhibin B and anti-Mullerian hormone as markers of gonadal function after treatment for medulloblastoma or posterior fossa ependymoma during childhood. J Pediatr. 2011;158(6):1016-1022.

29. Green DM, Zhu L, Zhang N, et al. Lack of specificity of plasma concentrations of inhibin $\mathrm{b}$ and follicle-stimulating hormone for identification of azoospermic survivors of childhood cancer: a report from the St Jude lifetime cohort study. J Clin Oncol. 2013;31(10):1324-1328.

30. Zebrack BJ, Gurney JG, Oeffinger K, et al. Psychological outcomes in long-term survivors of childhood brain cancer: a report from the childhood cancer survivor study. J Clin Oncol. 2004;22(6):999-1006.

31. Koeppel KM. Sperm banking and patients with cancer. Issues concerning patients and healthcare professionals. Cancer Nurs. 1995;18(4): 306-312.
Clinical Oncology in Adolescents and Young Adults

\section{Publish your work in this journal}

Clinical Oncology in Adolescents and Young Adults is an international, peer-reviewed, open access journal publishing original research, reports, editorials, reviews and commentaries on all aspects of epidemiology, diagnosis and treatment of cancers in adolescents and young adults. The manuscript management system is completely

\section{Dovepress}

online and includes a very quick and fair peer-review system. Visit http://www.dovepress.com/testimonials.php to read real quotes from published authors.

\footnotetext{
Submit your manuscript here: http://www.dovepress.com/clinical-oncology-in-adolescents-and-young-adults-journal
} 